\title{
SÍNTESE E CARACTERIZAÇÃO DE COPOLÍMEROS DO TIPO ABA PARA ENCAPSULAÇÃO DE HEMOGLOBINA BOVINA
}

\author{
Felipe F. Lima* e Cristina T. Andrade \\ Instituto de Macromoléculas Profa. Eloisa Mano, Universidade Federal do Rio de Janeiro, CT, Bl. J, CP 68525, $21945-970$ Rio \\ de Janeiro - RJ, Brasil
}

Recebido em 1/8/11; aceito em 19/11/11; publicado na web em 2/3/12

\begin{abstract}
SYNTHESIS AND CHARACTERIZATION OF ABA-TYPE COPOLYMERS FOR ENCAPSULATION OF BOVINE HEMOGLOBIN. The use of biopolymers for the development of oxygen carriers has been extensively investigated. In this work, three different ABA triblock copolymers were synthesized and used to encapsulate purified bovine hemoglobin, using a double emulsion technique. The effect of polymer composition, homogenization velocity, and addition of a surfactant, on the protein entrapment was evaluated. These copolymers, which have a hydrophilic block, achieved higher values of encapsulation efficiency than the corresponding homopolymers. The increase in homogenization strength also promoted an increase in encapsulation efficiency. Capsules formation occurred even in the absence of PVA.
\end{abstract}

Keywords: bovine hemoglobin; triblock copolymers; encapsulation.

\section{INTRODUÇÃO}

A necessidade de uma alternativa para transfusão alogênica de células vermelhas do sangue (hemácias) tem sido reconhecida há mais de um século. ${ }^{1-3}$ Embora mais segura, a transfusão de sangue alogênico ainda está associada a riscos para o receptor; os mais graves são as reações alérgicas, lesão pulmonar associada à transfusão (TRALI), erro na compatibilidade sanguínea e transmissão de infecções virais e bacterianas (hepatite, HIV, vírus Epstein-Barr). ${ }^{4,5} \mathrm{Os}$ riscos de transmissão da doença de Chagas através da transfusão de sangue tornam-se evidentes quando arquivos de doadores de sangue são revistos para a infecção pelo T. cruzi. Centros de hemoterapia no Brasil verificaram que um total de $1,09 \%$ de bolsas de sangue é descartado devido à infecção pelo T. cruzi. ${ }^{6}$ De fato, resultados de vários estudos clínicos prospectivos indicam que um regime de transfusão restritiva está associado com menor morbidade e mortalidade do que uma política liberal de transfusão. ${ }^{7-11}$ Além disso, os sistemas de saúde pública enfrentam uma elevação de custos, resultantes da morbidade relacionada à transfusão, bem como do contínuo aumento dos custos dos hemoderivados, por causa do crescente desequilíbrio entre a taxa decrescente de doação de sangue e a demanda cada vez maior. Foi previsto que os custos dos hemoderivados deverão dobrar até $2030 .{ }^{12,13}$ A fim de controlar tanto os riscos inerentes, bem como o aumento dos custos, as transfusões de sangue alogênico devem ser completamente evitadas ou pelo menos reduzidas a um mínimo absoluto durante os procedimentos cirúrgicos.

Substitutos para o sangue vêm sendo desenvolvidos há vários anos. Esses produtos não substituem o sangue em funções metabólicas mais complexas e interrelacionadas; a função desses produtos é transportar o oxigênio e o dióxido de carbono, por um período limitado de tempo. ${ }^{14}$ Para que se consiga o transporte/fornecimento de oxigênio às células, e minimizar os efeitos adversos de hemoglobina livre $(\mathrm{Hb})$ in vivo, várias alternativas foram propostas, dentre elas a encapsulação em nanopartículas, as quais podem funcionar como verdadeiros glóbulos vermelhos (RBC).

O uso de biopolímeros para o desenvolvimento de carreadores de oxigênio tem sido extensamente investigado devido à grande

\footnotetext{
*e-mail: felipelima@ima.ufrj.br
}

variedade de polímeros disponíveis no comércio, à possibilidade de se desenvolver polímeros sintéticos ou híbridos e à disponibilidade da nanotecnologia para a produção de nanopartículas em aplicações biomédicas. Comparadas aos lipossomas, as nanopartículas poliméricas são menos afetadas pelo extravasamento da proteína e a introdução de moléculas antiopsonizantes (por exemplo, PEG e heparina) na superfície da partícula garante meia-vida mais longa no sangue..$^{15,16}$

O polilactídeo (PLA) constitui-se no primeiro biopolímero a ser investigado como material de parede para a encapsulação da $\mathrm{Hb}$ e para outras aplicações biomédicas. Em trabalho pioneiro, a técnica de dupla emulsão, seguida pela evaporação do solvente orgânico, foi usada para a encapsulação da Hb. ${ }^{17}$

Poli(etileno glicol) (PEG), poli (ácido láctico) (PLA), poli (ácido glicólico) (PGA) e seus copolímeros (PLGA) são os polímeros mais aplicados no desenvolvimento de cápsulas poliméricas..$^{18-20} \mathrm{O}$ uso de outros tipos de polímeros, tais como o poli(glicol etilênico monometoxilado)-bloco-poli-D,L-polilactídeo (PELA) ${ }^{21}$ a poli( $(\varepsilon-$ caprolactona) (PCL) e a poli( $\varepsilon$-caprolactona-co-glicol etilênico), ${ }^{16}$ foi relatado na literatura.

Para superar as desvantagens decorrentes da natureza hidrofóbica do PLA, um segundo componente poli(etileno glicol) (PEG) tem sido amplamente utilizado para melhorar a biocompatibilidade de materiais com o sangue. O PEG é introduzido para formar um copolímero em bloco do tipo ABA, tais como o poli-DL-polilactídeo-co-poli(glicol etilênico) (PELA). ${ }^{22}$ Esta combinação e a natureza biocompatível do PELA criam um novo sistema biodegradável para a entrega de proteína/peptídeo e antígeno. Os domínios hidrofílicos de PEG no PELA, agindo como um estabilizador de proteína ou modificador da superfície hidrofóbica da rede de PLA, poderiam promover a estabilidade dos antígenos, aumentar a eficiência de encapsulação do antígeno e diminuir a quantidade de emulsificante usada na preparação de microesferas. ${ }^{23,24}$ Os copolímeros de e-caprolactona e L-lactídeo (PCLLA) têm sido amplamente estudados para aplicações médicas nos últimos anos, por apresentarem uma série de excelentes propriedades, incluindo biocompatibilidade, biodegradabilidade, processabilidade e uma ampla gama de propriedades. ${ }^{25}$

A encapsulação de hemoglobina em nano/micro sistemas poliméricos tem sido realizada usando diferentes técnicas. As técnicas mais aplicadas à base de polímeros são a técnica de dupla emulsão 
água/óleo/ água (w/o/w) ${ }^{21}$ e a de solvente de difusão/evaporação. ${ }^{16}$

Neste trabalho, três diferentes copolímeros do tipo ABA foram sintetizados e caracterizados. Os copolímeros 1 e 2 são copolímeros tribloco, PCL-PEG-PCL com diferentes razões molares, CL:EO. O copolímero 3 consiste de um bloco central de PEG, ligado às suas extremidades por copolímero aleatório de lactídeo e $\varepsilon$-caprolactona. Os copolímeros e os homopolímeros (PLA e PCL) também foram usados como matrizes encapsulantes da hemoglobina bovina ( $\mathrm{HbBv})$. Os efeitos da composição polimérica, da velocidade de homogeneização e da ausência de surfactante na eficiência de encapsulação foram avaliados.

\section{PARTE EXPERIMENTAL}

\section{Materiais}

A hemoglobina bovina foi isolada a partir de sangue bovino e purificada de acordo com o método descrito por Lima e Andrade. ${ }^{26} \mathrm{O}$ L,L-lactídeo, [(3S)-cis-3,6-dimetil-1,4-dioxano-2,5-diona], a e-caprolactona, e o 2-etil-hexanoato de estanho $\left(\mathrm{SnOct}_{2}\right)$ foram fornecidos pela Aldrich (Saint Louis, EUA). O poli(glicol etilênico) (PEG), $M_{n}$ $=6000$, foi fornecido pela Dow Brasil S.A.(Jundiaí, Brasil). O PVA foi fornecido pela Vetec Química Fina Ltda. (Duque de Caxias, Rio de Janeiro) com 86,5-89,5\% de hidrólise.

\section{Metodologia}

\section{Síntese dos copolímeros}

Os copolímeros 1 e 2 ( $\mathrm{Co} 1$ e Co2) foram sintetizados mantendo-se uma razão pré-estabelecida entre os blocos hidrofóbico e hidrofílico, ou seja, razões molares calculadas entre as unidades repetitivas de e-caprolactona (CL) e de PEG (representado por EO), CL:EO, de 2,0 e 4,0. O copolímero (Co3) foi sintetizado com razões molares calculadas, LA(+CL):EO, de 4,0. Foi usada uma razão mássica de 3:2 para LA:CL. O cálculo de cada material foi feito para uma massa total de $20 \mathrm{~g}$.

As polimerizações foram realizadas de acordo com o método descrito na literatura. ${ }^{27} \mathrm{Em}$ glove bag, sob atmosfera de nitrogênio seco, quantidades de PEG6000 $\left(\mathrm{M}_{\mathrm{n}}=6000\right)$ e $\mathrm{SnOct}_{2}$ foram previamente pesadas. Foi utilizado 0,05 mol de $\mathrm{SnOct}_{2}$ por mol de grupamento hidroxila de PEG. O tubo foi selado e imerso em banho de óleo de silicone a $120^{\circ} \mathrm{C}$ por 10 min e, posteriormente, resfriado sob temperatura ambiente. Massas pré-estabelecidas de L,L-lactídeo e e-caprolactona foram vertidas no tubo sob atmosfera de nitrogênio. Os tubos foram novamente selados e imersos em banho com temperatura controlada durante $48 \mathrm{~h}$. Os copolímeros 1 e 2 ( $\mathrm{Co} 1$ e $\mathrm{Co} 2)$ foram sintetizados a $140{ }^{\circ} \mathrm{C}$ e o copolímero 3 (Co3) a $120^{\circ} \mathrm{C}$.

Os copolímeros obtidos foram purificados por dissolução em clorofórmio e precipitados em metanol (três vezes), filtrados e secos a $55^{\circ} \mathrm{C}$ em estufa ventilada por $24 \mathrm{~h}$.

\section{Caracterização dos copolímeros}

\section{Espectroscopia de absorção na região do infravermelho (FTIR)}

As amostras foram caracterizadas por espectroscopia de absorção na região do infravermelho, em espectrofotômetro Excalibur 3100 FT-IR da marca Varian (Mulgrave, Victoria, Austrália). As análises foram realizadas em filme vazado de solução de clorofórmio.

\section{Espectroscopia de ressonância magnética de hidrogênio $\left({ }^{1}\right.$ H NMR)}

Os espectros de ${ }^{1} \mathrm{H}$ NMR foram obtidos a partir de soluções de clorofórmio deuterado $\left(\mathrm{CDCl}_{3}\right)$, em espectrofotômetro Varian Mercury VX 300 (Palo Alto, CA, EUA), na frequência de $300 \mathrm{MHz}$ para ${ }^{1} \mathrm{H}$. Os espectros tiveram a finalidade de determinar a razão molar CL:EO nos Co1 e Co2 e estimar as composições relativas. A composição LA:EO no Co3 foi determinada pela Equação $1 .{ }^{28}$

$$
\frac{\mathrm{LA}}{\mathrm{EO}}=\frac{\frac{\mathrm{I}_{\mathrm{CH}_{3}}}{3}}{\frac{\mathrm{I}_{\mathrm{CH} 2}}{4}}=1,333 \times \frac{I_{\mathrm{CH}_{3}}}{I_{\mathrm{CH}_{2}}}
$$

onde $\mathrm{I}_{\mathrm{CH} 3}$ é a área correspondente ao grupo metila do PLA (1,4-1,6 $\left.\delta\right)$; $\mathrm{I}_{\mathrm{CH} 2}$ é a área correspondente ao grupo metileno do PEG (3,4-3,7 $\left.\delta\right)$.

As razões molares CL:EO nos Co1 e $\mathrm{Co} 2$ foram determinadas pela Equação 2.

$$
\frac{\mathrm{CL}}{\mathrm{EO}}=\frac{\frac{\mathrm{I}_{\mathrm{CH}_{2}}}{2}}{\frac{\mathrm{I}_{\mathrm{CH} 2}}{4}}=2 \times \frac{I_{\mathrm{CH}_{2}}}{I_{\mathrm{CH}_{2}}}
$$

onde $\mathrm{I}_{\mathrm{CH} 2}$ é a área correspondente ao grupo metileno do PCL $(4,0 \delta)$; $\mathrm{I}_{\mathrm{CH} 2}$ é a área correspondente ao grupo metileno do PEG (3,4-3,7 $\left.\delta\right)$.

\section{Espectroscopia de ressonância magnética de carbono ( 13 C NMR)}

$\mathrm{O}$ espectro do $\mathrm{Co} 3$ foi obtido a partir de solução de clorofórmio deuterado $\left(\mathrm{CDCl}_{3}\right)$ em espectrofotômetro Varian Mercury VX 300 (Palo Alto, CA, EUA), na frequência de $75 \mathrm{MHz}$ para ${ }^{13} \mathrm{C}$.

\section{Difração de raios $X$}

As amostras foram analisadas em um difratômetro de raios $X$ da marca Rigaku RU200R (Osaka, Japão), em velocidade de $2^{\circ}(2 \theta) / \mathrm{min}$ com um passo de $0,05^{\circ}(2 \theta)$ e equipado com uma fonte de radiação do tipo $\mathrm{CuK}_{\alpha}(\lambda=0,15418 \mathrm{~nm})$ gerada a $40 \mathrm{kV}$ e $50 \mathrm{~mA}$. A radiação foi detectada por meio de um detector proporcional. Os difratogramas foram obtidos no modo de reflexão na faixa de 5 a $40^{\circ}(2 \theta)$.

$\mathrm{O}$ porcentual de cristalinidade dos materiais sintetizados foi obtido pelo método de ajuste dos picos dos difratogramas, com o auxílio do software estatístico Fityk versão 0.9.3 (GNU General Public License - 2010).

O modelo matemático utilizado para o ajuste das gaussianas em cada difratograma foi o de Levenberg-Marquardt. Considerou-se para os cálculos a razão do somatório das áreas dos picos cristalinos pela área total de todas as gaussianas, no intervalo de $5^{\circ}$ a $40^{\circ}(2 \theta)$ de acordo com a Equação 3.

$$
X c(\%)=\frac{I c}{(I c+I a)} \times 100
$$

onde Xc é o grau de cristalinidade; Ic é o somatório das áreas dos picos cristalinos; Ia é a área do halo amorfo.

\section{Análise da tensão interfacial}

As medidas de tensão interfacial foram realizadas pelo método Du Noüy Ring no tensiômetro da KSV Instruments Ltd. (Helsink, Finland), equipado com anel de platina. A fase orgânica com os copolímeros dissolvidos em $20 \mathrm{~mL}$ de diclorometano foi vertida em recipiente padrão. Em seguida, água ultrapura (Milli-Q) foi vertida lentamente sobre a fase orgânica. As medidas de tensão interfacial foram realizadas a temperatura ambiente $\left(25^{\circ} \mathrm{C}\right)$.

\section{Encapsulação da hemoglobina bovina}

A primeira fase aquosa $\left(\mathrm{w}_{1}\right)$, constituída de $\mathrm{HbBv}(14 \mathrm{~g} / \mathrm{dL})$ dissolvida em solução tampão Tris. $\mathrm{HCl} \mathrm{pH}$ 7,4 foi gotejada na solução orgânica (fase o) composta de copolímero dissolvido a $1,5 \%(\mathrm{~m} / \mathrm{m})$ em diclorometano. Essa emulsão $\left(\mathrm{w}_{1} / \mathrm{o}\right)$ foi homogeneizada a $5000 \mathrm{rpm}$ durante $15 \mathrm{~s}$ com o auxílio de um dispersador de alta performance marca IKA Works, modelo Ultra Turrax T50 (Wilmington, NC, EUA). 
Esta primeira emulsão $\left(\mathrm{w}_{1} / \mathrm{o}\right)$ foi vertida na segunda fase aquosa $\left(\mathrm{w}_{2}\right)(\mathrm{com}$ PVA a 0 e $1 \% \mathrm{~m} / \mathrm{m})$ a fim de formar a dupla emulsão $\left(\mathrm{w}_{1} / \mathrm{o} /\right.$ $\mathrm{w}_{2}$ ). Para a formação da dupla emulsão, o sistema foi homogeneizado duas vezes durante 30 e $90 \mathrm{~s}$. A Tabela 3 mostra as condições de formulação das cápsulas produzidas, onde se manteve constante a velocidade de homogeneização a $9000 \mathrm{rpm}$ e se variou a concentração de PVA $(0$ e $1 \%$ m/m). Para a velocidade de homogeneização de 15000 rpm, empregou-se uma concentração de PVA na segunda fase aquosa de $1 \% \mathrm{~m} / \mathrm{m}$.

As amostras foram submetidas à leve agitação magnética por 4 h. Após a evaporação do solvente, as partículas foram recuperadas por centrifugação. O sobrenadante foi descartado e $200 \mathrm{~mL}$ de água destilada e deionizada foram adicionados ao retentado. Após a ressuspensão, as partículas foram recuperadas após outra centrifugação. Esse processo foi realizado 3 vezes até a recuperação final. A formação das cápsulas foi realizada em triplicata.

\section{Eficiência de encapsulação}

A eficiência de encapsulação representa a porcentagem de $\mathrm{HbBv}$ encapsulada em relação à concentração inicial total de HbBv usada no processo de encapsulação. A concentração de $\mathrm{HbBv}$ encapsulada foi determinada indiretamente, ou seja, pela medida da diferença de quantidade de $\mathrm{HbBv}$ entre a concentração inicial de $\mathrm{HbBv}\left(\mathrm{HbBv}_{\text {total }}\right)$ e a concentração de $\mathrm{HbBv}$ livre no sobrenadante $\left(\mathrm{HbBv}_{\text {livre }}\right)$ após centrifugação. Portanto, EE\% é expresso de acordo com Equação $4 .{ }^{29}$

A concentração de $\mathrm{HbBv}$ foi determinada pelo método da cianomete-hemoglobina (HiCN). O sobrenadante coletado $(1 \mathrm{~mL})$ foi adicionado a $2 \mathrm{~mL}$ do reagente de Drabkin, homogeneizado por $3 \mathrm{~min}$ e analisado por espectrometria a $540 \mathrm{~nm}$ (espectrofotômetro Varian CARY100, Mulgrave, Victoria, Austrália). A concentração de HbBv foi determinada em relação a uma curva de calibração, preparada através de diluições de solução padrão de HiCN. As determinações foram realizadas em triplicata.

$$
E E \%=\frac{\left(H b B v_{\text {total }}-H b B b_{\text {livre }}\right)}{H b B v_{\text {total }}} \times 100 \%
$$

\section{RESULTADOS E DISCUSSÃO}

O 2-etil-hexanoato de estanho ou octoato de estanho é um catalisador muito estudado e utilizado para polimerizações de lactonas. Além de muito eficiente, oferece baixo risco de racemização e possui baixa toxicidade. Por isso, o seu uso foi aprovado pelo FDA como aditivo alimentar.

O mecanismo de polimerização por abertura de anel, na presença de substâncias hidroxiladas, foi descrito por Kricheldorf e colaboradores.$^{30}$ Copolímeros do tipo ABA (PECL e PELACL) foram obtidos pela mistura de lactídeo, e-caprolactona, $\mathrm{PEG}$, na presença do iniciador octoato de estanho, conforme relatado por outros autores para a síntese de copolímeros em bloco de PEG e outras lactonas. ${ }^{31,32}$

As reações de polimerização foram caracterizadas por um rápido aumento de viscosidade do meio reacional. Os três copolímeros obtidos foram secos até peso constante e apresentaram rendimentos de 84,$9 ; 88,9$ e $60,6 \%$ para as amostras Co1, Co2 e Co3, respectivamente. Os produtos $\mathrm{Co} 1$ e $\mathrm{Co} 2$ apresentaram aspecto sólido e cor branca, e a amostra Co3 apresentou aspecto borrachoso e cor âmbar.

Assim como as amostras de PLA e PCL, os copolímeros Co1, $\mathrm{Co} 2$ e $\mathrm{Co} 3$ foram caracterizados por FTIR, e os espectros obtidos são mostrados na Figura 1. As três bandas intensas, que aparecem no espectro da Figura 1a, são características do PLA. A absorção a 1757 $\mathrm{cm}^{-1}$ é atribuída ao estiramento do grupamento $\mathrm{C}=\mathrm{O}$. As bandas a 1181 e $1092 \mathrm{~cm}^{-1}$ são atribuídas, respectivamente, ao estiramento assimétrico e simétrico do grupamento $\mathrm{C}-\mathrm{C}(=\mathrm{O})-\mathrm{O}$. A ausência de uma banda intensa na região $3500-3000 \mathrm{~cm}^{-1}$ (estiramento do grupamento $\mathrm{O}-\mathrm{H}$ ) é um indicativo da ausência de subprodutos de hidrólise do PLA. A Figura $1 \mathrm{~b}$ mostra o espectro da policaprolactona. A banda a $1726 \mathrm{~cm}^{-1}$ é atribuída ao estiramento de $\mathrm{C}=\mathrm{O}$ e as bandas a 2944 e $2865 \mathrm{~cm}^{-1}$ são atribuídas ao estiramento dos grupamentos $\mathrm{C}-\mathrm{H}$.

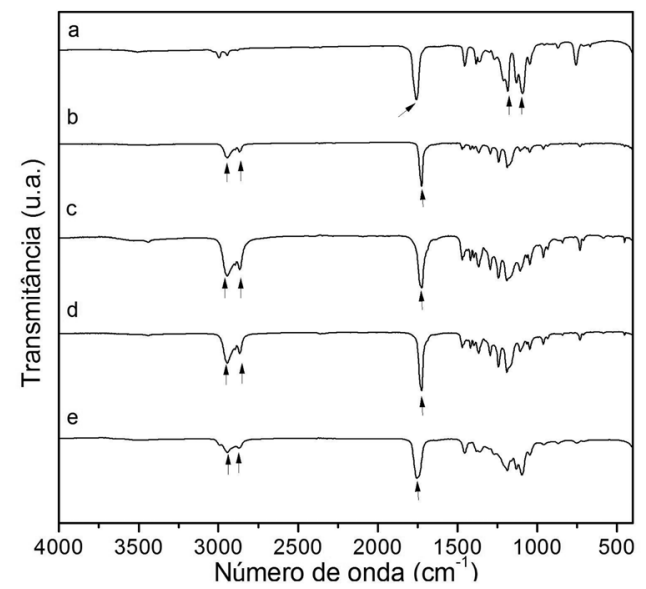

Figura 1. Espectros de absorção da região do infravermelho do PLA (a), $P C L(b), C o 1$ (c), $\mathrm{Co} 2$ (d) e $\operatorname{Co} 3(e)$

Os espectros das amostras Co1 e Co2 (Figura 1c e 1d) mostram que houve redução na banda a $3400 \mathrm{~cm}^{-1}$. As bandas a 1726 e 1726 $\mathrm{cm}^{-1}$ são atribuídas ao estiramento do grupamento $\mathrm{C}=\mathrm{O}$ das amostras Co1 e Co2, respectivamente. As bandas a 2944 e 2951 cm$^{-1}$ são atribuídas ao estiramento de $\mathrm{C}-\mathrm{H}$, assim como as bandas a 2867 e $2867 \mathrm{~cm}^{-1}$ das amostras $\mathrm{Co} 1$ e Co2, respectivamente.

A Figura 1e mostra o espectro obtido para o produto Co3. O espectro apresenta bandas características dos blocos constituintes de PLA, PCL e PEG, e sugerem a formação do copolímero. Pode ser observada a redução na intensidade das bandas a $837 \mathrm{~cm}^{-1}$ e na região de $1111 \mathrm{~cm}^{-1}$. No entanto, a técnica de FTIR não permite afirmar que os produtos PEG, PLA e PCL estejam unidos por ligação covalente resultante da poliesterificação, ou que os produtos formados não sejam apenas misturas poliméricas, mas corrobora os resultados mostrados na Figura 2.

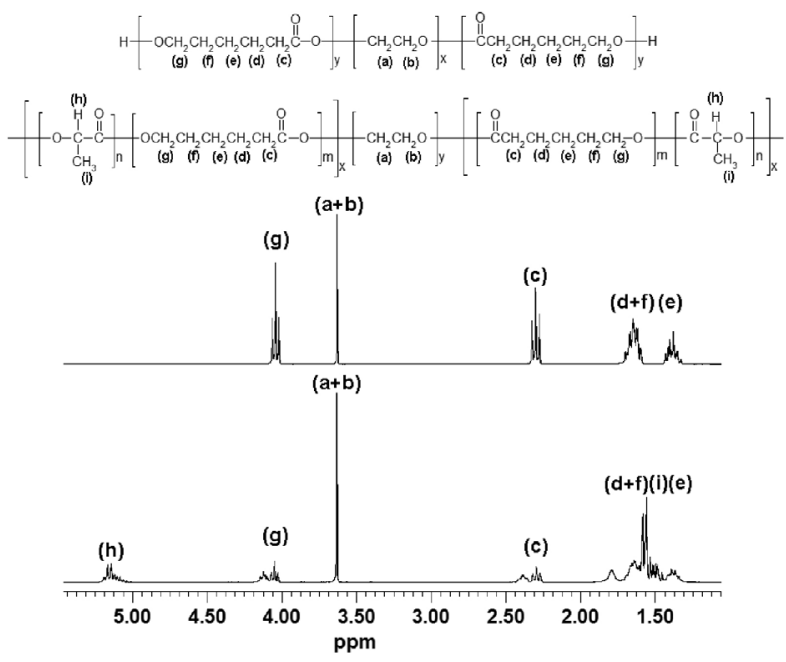

Figura 2. Espectros de ${ }^{l} \mathrm{H}$ NMR para os produtos Co2 (a) e Co3 (b)

Os espectros de ${ }^{1} \mathrm{H}$ NMR, obtidos para as amostras Co1 e Co2 (Figura 2a), apresentaram deslocamentos químicos semelhantes. Os dois espectros apresentaram os sinais a 1,37; 1,64; 2,3 e 4,06 ppm, atribuídos aos átomos de hidrogênio dos diferentes grupos metilênicos 
$\left(-\mathrm{CH}_{2}-\right)$, característicos do bloco de PCL. Os sinais em torno de 3,6 ppm são característicos das unidades $-\mathrm{CH}_{2}-$ da cadeia principal do bloco PEG. Os átomos de hidrogênio do grupo metileno do PEG, na ligação entre PEG e PCL, apareceram a 4,3 ppm, juntamente com o átomo de hidrogênio das unidades finais hidroxiladas do segmento caproila. A presença deste sinal a 4,3 ppm confirma a formação do copolímero em bloco PCL-PEG-PCL.

As razões molares CL:EO das amostras $\mathrm{Co} 1$ e $\mathrm{Co} 2$ foram determinadas de acordo com a Equação 2. Os valores encontrados foram 2,23 e 5,11 para as amostras $\mathrm{Co} 1$ e $\mathrm{Co} 2$, respectivamente. Os valores das razões molares nos produtos mostraram-se superiores àqueles usados na alimentação (2,0 e 4,0, respectivamente). Este resultado pode ser explicado de duas maneiras: pelo fato do PEG não ter reagido totalmente, ou por espécies ricas em PEG terem sido removidas durante o processo de purificação.

A Figura $2 \mathrm{~b}$ mostra o espectro de ${ }^{1} \mathrm{H}$ NMR obtido para o produto Co3. O espectro mostra picos a $1,56 \mathrm{ppm}\left(-\mathrm{CH}_{3}\right.$, PLA), e a 5,14 ppm (-CH, PLA), na região 1,38-1,79 ppm $\left(\mathrm{CH}_{2}-\mathrm{CH}_{2}-\mathrm{CH}_{2}, \mathrm{PCL}\right)$, a $2,3 \mathrm{ppm}\left(-\mathrm{CH}_{2} \mathrm{CO}, \mathrm{PCL}\right)$ e a $4,05 \mathrm{ppm}\left(-\mathrm{CH}_{2}-\right.$, PCL). Os picos característicos das ligações LA-CL da amostra $\mathrm{Co} 3$ foram detectados em 2,39; 4,12 e 5,14 ppm nos espectros de ${ }^{1} \mathrm{H}$ NMR, o que indica a ocorrência de reação de transesterificação para a formação do copolímero aleatório. O sinal em torno de 3,6 ppm é atribuído aos átomos de hidrogênio do grupamento metileno $\left(-\mathrm{CH}_{2}-\right)$ do bloco PEG. A razão molar LA:CL na amostra $\mathrm{Co} 3$ foi maior do que na alimentação, enquanto que as razões CL:EO $(0,72)$ foram menores do que na alimentação $(1,0)$. Estes resultados podem ser explicados em função da baixa reatividade da caprolactona,${ }^{33}$ a temperaturas mais baixas que $140^{\circ} \mathrm{C}$. Foram realizadas análises por cromatografia por exclusão por tamanho. Os perfis das curvas de eluição mostraram o caráter monomodal dos três copolímeros.

A fim de confirmar a formação de um copolímero aleatório, o espectro de ${ }^{13} \mathrm{C}$ NMR foi realizado para o produto Co3. A Figura 3 mostra esse espectro. Bero e colaboradores ${ }^{34-36}$ relataram que a análise por ${ }^{13} \mathrm{C}$ NMR pode fornecer informações importantes sobre a sequência de unidades de caproila e de lactidila. No espectro de ${ }^{13} \mathrm{C}$ NMR do copolímero aleatório de LA e CL, não apenas os picos atribuídos às sequências de LLL e CCC aparecem, como também os picos atribuídos às sequências CCL, LCL, CLC e CLL, resultantes da reação de transesterificação.

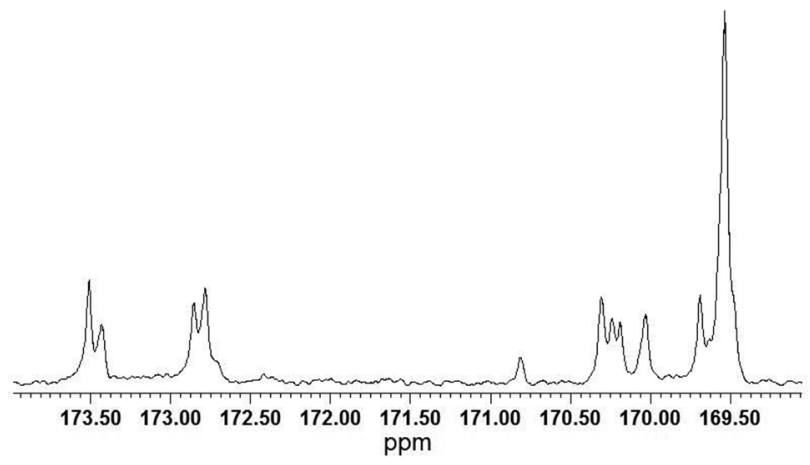

Figura 3. Espectro de ${ }^{13} \mathrm{C}$ NMR para o produto $\mathrm{Co} 3$

De acordo com a análise proposta por alguns autores, ${ }^{37} \mathrm{O}$ espectro obtido para o produto Co3 também indica a tendência à formação de um copolímero aleatório no bloco hidrofóbico. No entanto, os resultados experimentais revelaram a predominância de sequências de lactidila, associadas com blocos curtos de PLA. Este resultado também pode ser explicado levando-se em conta os dados de reatividade relativa relatados na literatura, os quais indicam uma maior reatividade do monômero LA em ambos os tipos de grupos terminais das cadeias ativas, lactidila e caproila, em comparação com os grupos terminais da CL.

A difração de raios $\mathrm{X}$ é uma técnica muito utilizada na caracterização e identificação de materiais de estrutura cristalina. As amostras dos copolímeros usadas para essa análise foram preparadas sem qualquer tratamento térmico prévio, com o objetivo de evitar-se alteração de cristalinidade. A Figura 4a mostra o difratograma do PEG6000, no qual se pode observar os picos característicos aos

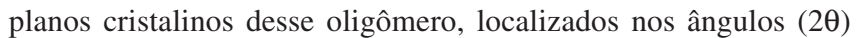
$19,48^{\circ}$ e $23,54^{\circ}$. Para a PCL, a estrutura cristalina é atribuída a uma

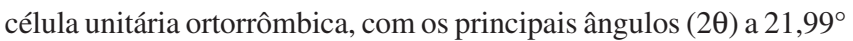
e $24,31^{\circ}$ (Figura 4b).

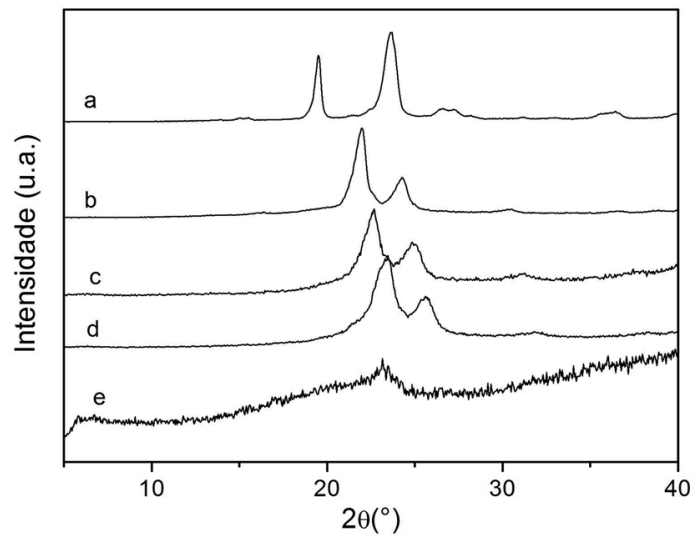

Figura 4. Difratogramas de raios X para os produtos PEG6000(a), PCL (b), $\mathrm{Col}(\mathrm{c}), \mathrm{Co} 2(d)$ e $\operatorname{Co3}(e)$

Na Figura 4, estão incluídos também os difratogramas dos produtos Co1, Co2 e Co3. Nos difratogramas obtidos para os produtos $\mathrm{Co} 1$ e $\mathrm{Co} 2$, embora os perfis sejam semelhantes ao perfil obtido para a PCL, os picos são um pouco mais largos e menos intensos, e foram deslocados para maiores valores de $2 \theta$. Esse resultado revela uma menor cristalinidade e a presença de cristais com menores distâncias interlamelares. Por outro lado, o produto $\mathrm{Co} 3$ (Figura 4e) apresentou uma redução significativa na cristalinidade. Esse resultado pode ser explicado como uma consequência da dificuldade de cristalização dos segmentos de LA e CL, distribuídos estatisticamente no bloco hidrofóbico do $\mathrm{Co} 3$, o que corrobora os dados de ${ }^{13} \mathrm{C}$ NMR.

O grau de cristalinidade pode ser calculado a partir da relação entre a área sob os picos cristalinos e a área total (área cristalina + halo amorfo). A Tabela 1 mostra os resultados obtidos para o grau de cristalinidade dos produtos. Os resultados revelam que os produtos $\mathrm{Co} 1$ e $\mathrm{Co} 2$ apresentaram valores inferiores àqueles dos homopolímeros, independentemente da razão molar. A adição de LA ao meio reacional para a obtenção do produto $\mathrm{Co} 3$ teve grande influência na redução do grau de cristalinidade.

Tabela 1. Graus de cristalinidade calculados a partir dos difratogramas de raios $\mathrm{X}$

\begin{tabular}{cc}
\hline Amostra & Cristalinidade $(\%)$ \\
\hline PEG6000 & 68,7 \\
PCL & 67,7 \\
Co1 & 34,4 \\
Co2 & 30,0 \\
Co3 & 9,3 \\
\hline
\end{tabular}

Embora a tensão interfacial tenha uma forte influência sobre o processo de emulsificação água em óleo, é apenas um dos parâmetros 
que controlam a estabilidade da emulsão final. No entanto, a medição da tensão interfacial avalia o destino de um surfactante em uma interface; por exemplo, a complexação com ou deslocamento por uma das substâncias dissolvidas em uma das fases da emulsão. A tensão interfacial também permite que se compare a afinidade de diferentes surfactantes para uma interface específica.$^{38} \mathrm{O}$ experimento realizado teve como objetivo investigar a possível atividade de revestimento dos polímeros na interface, quando dissolvido na fase óleo.

Bouillot e colaboradores ${ }^{39}$ relataram que copolímeros PLA-PEG, usados para formar a matriz de microesferas também poderiam participar na estabilização de emulsões. Esses copolímeros, como aqueles usados no presente estudo, têm propriedades anfifílicas. Assim, eles reduzem a tensão interfacial da emulsão w/o durante a preparação de microesferas. Além disso, os blocos de PEG estão envolvidos na estabilização estérica das gotas e, consequentemente, das microesferas.

A Tabela 2 mostra os valores de tensão interfacial obtidos para os homopolímeros e copolímeros. A tensão interfacial entre diclorometano/água é de 27,06 mN/m. Os homopolímeros PLA e PCL, que não possuem grupos hidrofílicos, não apresentam qualquer adsorção significativa na interface diclorometano/água. Por isso, para esses homopolímeros, não se observou redução na tensão interfacial w/o após a sua adição.

Tabela 2. Valores de tensão interfacial

\begin{tabular}{cc}
\hline Amostra & Tensão interfacial $(\mathrm{mN} / \mathrm{m})$ \\
\hline PLA & 22,5 \\
PCL & 27,3 \\
Co1 & 9,3 \\
Co2 & 17,0 \\
Co3 & 16,4 \\
\hline
\end{tabular}

Os copolímeros sintetizados possuem em suas cadeias um bloco central de PEG. Esse bloco hidrofílico teve papel importante na redução da tensão interfacial, devido à sua forte adsorção na interface diclorometano/água. O menor valor encontrado de tensão interfacial foi para o produto Co1. Esse resultado era esperado e corrobora os dados das análises de NMR. Por possuir a menor razão molar CL:EO, o efeito do produto Co1 sobre a tensão interfacial é menor também.

Nesse trabalho, foi investigada a eficiência de encapsulação da $\mathrm{HbBv}$ pelos produtos sintetizados. A perda da proteína encapsulada durante o processo de fabricação de microesferas resulta essencialmente do fato de que a proteína na fase aquosa interna tende a se difundir para a fase aquosa externa. Consequentemente, o valor de EE\% pode ser afetado pelos seguintes fatores: estabilidade da emulsão w/o e w/o/w; taxa de remoção de solvente; interações entre polímeros, componente ativo, solventes e aditivos e, tamanho de partícula. ${ }^{38,40,41}$ Além disso, esses fatores são influenciados pela natureza hidrofílica/hidrofóbica dos materiais utilizados para a preparação de microesferas.

A Tabela 3 mostra os efeitos das condições de formulação das microcápsulas sobre os valores de $\mathrm{EE} \%$ para $\mathrm{HbBv}$. Foram avaliados os efeitos da velocidade de homogeneização, da composição polimérica e da ausência de PVA na fase externa da dupla emulsão. $\mathrm{O}$ aumento na energia aplicada na homogeneização do sistema de dupla emulsão proporcionou uma elevação nos valores de EE\%.

A ausência do surfactante, PVA, na fase aquosa externa levou à redução nos valores de EE\%. O PVA tem o papel de estabilizar a dupla emulsão, o que pode explicar a maior eficiência de encapsulação de HbBv quando é adicionado. No entanto, mesmo sem a adição de PVA, a redução dos valores de EE\% para as
Tabela 3. Valores de eficiência de encapsulação

\begin{tabular}{lccc}
\hline Polímero & \multicolumn{3}{c}{ Condições de formulação de cápsulas } \\
& 9000 rpm & 15000 rpm & 9000 rpm \\
& 1\% PVA & $29,0 \pm 1,1$ & $15,7 \pm 1,3$ \\
\hline PLA & $26,8 \pm 1,5$ & $34,2 \pm 1,5$ & $21,1 \pm 2,1$ \\
PCL & $32,7 \pm 1,3$ & $68,3 \pm 1,5$ & $60,9 \pm 1,8$ \\
Co1 & $65,1 \pm 1,7$ & $59,1 \pm 1,9$ & $51,0 \pm 1,1$ \\
Co2 & $56,4 \pm 1,0$ & $54,2 \pm 1,0$ & $46,2 \pm 1,9$ \\
Co3 & $51,3 \pm 1,2$ & &
\end{tabular}

microcápsulas formadas pelos copolímeros não foi significativa, pois o caráter anfifílico dos copolímeros garantiu a estabilidade da emulsão.

As microcápsulas formadas pelos copolímeros tiveram valores de EE\% superiores àqueles observados para os homopolímeros, PLA e PCL. Esse resultado está diretamente relacionado à presença de um bloco hidrofílico no meio da cadeia. Os copolímeros participaram mais da estabilização da emulsão ao apresentarem menores valores de tensão interfacial, o que garantiu valores superiores de EE\%. Para os copolímeros, os valores de EE\% podem estar relacionados aos valores encontrados para a tensão interfacial. Outro fator que pode ter contribuído para a melhor eficiência de encapsulação da $\mathrm{HbBv}$ pelos copolímeros está relacionado à presença do segmento hidrofílico de PEG na cadeia polimérica, com uma maior afinidade com as moléculas $\mathrm{HbBv}^{42}$

\section{CONCLUSÃO}

No presente trabalho, três copolímeros tribloco do tipo ABA foram sintetizados e usados para encapsular a hemoglobina bovina, utilizando a técnica de dupla emulsão. Os copolímeros tiveram suas estruturas confirmadas e estudadas por meio de análises por FTIR, ${ }^{1} \mathrm{H}$ NMR e ${ }^{13} \mathrm{C}$ NMR. A introdução do bloco hidrofílico, PEG, contribuiu para redução nos valores de tensão interfacial. O bloco PEG dos copolímeros atuou efetivamente na interface para estabilizar a emulsão e contribuiu para o aumento dos valores de eficiência de encapsulação. Foi observada uma correlação entre os valores de tensão interfacial e a eficiência de encapsulação. $\mathrm{O}$ aumento na energia de homogeneização contribuiu para promover o aumento na eficiência de encapsulação. Os copolímeros podem ser usados para a formação de microcápsulas, na ausência de PVA, por levarem a uma pequena redução nos valores de eficiência de encapsulação de $\mathrm{HbBv}$.

\section{AGRADECIMENTOS}

Ao CNPq pelo suporte financeiro.

\section{REFERÊNCIAS}

1. Winslow, R. M.; Vox Sang. 2006, 91, 102.

2. Habler, O.; Pape, A.; Meier, J.; Zwibler, B.; Anaesthesist 2005, 54, 741.

3. Ness, P. M.; Cushing, M. M.; Arch. Pathol. Lab. Med. 2007, 131, 734.

4. Goodnough, L. T.; Crit. Care Med. 2003, 31, S678.

5. Madjdpour, C.; Heindl, V.; Spahn, D. R.; Minerva Anestesiologica 2006, 72,283 .

6. Wendel, S.; Shikanai Yasuda, M. A.; Silva, G. R.; Rev. Bras. Hematol. Hemoter. 2004, 26 (supl.2), 282.

7. Hebert, P. C.; Wells, G. A.; Blajchman, M. A.; Marshall, J.; Martin, C.; Pagliarello, G.; Tweeddale, M.; Schweitzer, I.; Yatisir, E.; New Engl. J. Med. 1999, 340, 409. 
8. Vincent, J. L.; Baron, J. F.; Reinhart, K.; Gattinoni, L.; Thijs, L.; Webb, A.; Meier-Hellmann, A.; Nollet, G.; Peres-Bota, D.; J. Am. Med. Assoc. 2002, 288, 1499.

9. Corwin, H. L.; Gettinger, A.; Pearl, R. G.; Fink, M. P.; Levy, M. M.; Abraham, E.; Maclntyre, N. R.; Shabot, M. M.; Duh, M. S..; Shapiro, M. J.; Crit. Care Med. 2004, 32, 39.

10. Taylor, R. W.; O'Brien, J.; Trottier, S. J.; Manganaro, L.; Cytron, M.; Lesko, M. F.; Arnzen, K.; Cappadoro, C.; Fu, M.; Plisco, M. S.; Sadaka, F. G.; Veremakis, C.; Crit. Care Med. 2006, 34, 2302.

11. Palmieri, T. L.; Caruso, D. M.; Foster, K. N.; Cairns, B. A.; Peck, M. D.; Gamelli, R. L.; Mozingo, D. W.; Kagan, R. J.; Wahl, W.; Kemalyan, N. A.; Fisch, J. S.; Gomez, M.; Sheridan, R. L.; Faucher, L. D.; Latenser, B. A.; Gibran, N. S.; Klein, R. L.; Solem, L. D.; Saffle, J. R.; Morris, S. E.; Jeng, J. C.; Voigt, D.; Howard, P. A.; Molitor, F.; Greenhalgh, D. G.; Crit. Care Med. 2006, 34, 1602.

12. Varney, S. J.; Guest, J. F.; Transfusion Med. 2003, 12, 205.

13. Goodnough, L. T.; Shander, A.; Brecher, M. E.; Lancet 2003, 361, 161.

14. Moore, E. E.; J. Am. Coll. Surg. 2003, 196, 1.

15. Chauvierre, C.; Marden, M.; Vauthier, C.; Labarre, D.; Couvreu, P.; Leclerc, L.; Biomaterials 2004, 25, 3081.

16. Zhao, J.; Liu, C. S.; Yuan, Y.; Tao, X. Y.; Shan, X. Q.; Sheng, Y.; Wu, F.; Biomaterials 2007, 28, 1414.

17. Chang, T. M. S.; J. Bioeng. 1976, 1, 25.

18. Przybelski, R. J.; Daily, E. V.; Birnbaum, M. L. Em Advances in blood substitutes: Industrial opportunities and medical challenges; Winslow, R. M.; Vandegriff, K. D.; Intaglietta, M., eds.; Birkhauser: Boston, 1997.

19. Yu, W. P.; Chang, T. M. S.; Artif. Cells Blood Subst. Immobil. Biotechnol. 1996, 24, 169.

20. Chang, T. M. S.; Crit. Care Med. 2004, 32, 612.

21. Meng, F. T.; Ma, G. H.; Liu, Y. D.; Qiu, W.; Su, Z. G.; Colloids Surf., $B$ 2004, 33, 177 .

22. Deng, X. M.; Li, X. H.; Yuan, M. L.; Xiong, C. D.; Hyang, Z. T.; Jia, W. X.; Zhang, Y. H.; J. Controlled Release 1999, 58, 123.
23. Li, X. W.; Xiao, J.; Deng, X. M.; Li, X. Y.; Wang, H. L.; Jia, W. X.; Zhang, W. B.; Men, L.; Yang, Y.; Zheng, Z. X.; J. Appl. Polym. Sci. 1997, 66, 583.

24. Li, X.; Deng, X.; Huang, Z.; Pharm. Res. 2001, 18, 117.

25. Ge, H.; Hu, Y.; Yang, S.; Jiang, X.; Yang, C.; J. Appl. Polym. Sci. 2000, 75,874 .

26. Lima, M. C. P.; Andrade, C. T.; Artif. Cells Blood Subst. Immobil. Biotechnol. 2007, 35, 431.

27. Drumond, W. S.; Hui, S. W.; Mothé, C. G.; Polímeros: Ciência e Tecnologia 2004, 14, 74.

28. Li, S. M.; Rashkov, I.; Espartero, J. L.; Manolova, N.; Vert, M.; Macromolecules 1996, 29, 57.

29. Poulain, N.; Dez, I.; Lasne, M. C.; Prud'homme, M. P.; Nakache, E.; J. Controlled Release 2003, 92, 27.

30. Kricheldorf, H. R.; Lee, S. R.; Polymer 1995, 36, 2995.

31. Peter, J. A.; Weld, IN'T.; Velner, E. M.; Witte, P. U. D.; Hambuis, J.; Dijksta, P. J.; Feijen, J.; J. Polym. Sci., Part A: Polym. Chem. 1997, 35, 219.

32. Lang, M.; Bei, J.; Wang, S.; J. Biomater. Sci., Polym. 1999, 10, 501.

33. Garkhal, K.; Verma, S.; Jonnalagadda, S.; Kumar, N.; J. Polym. Sci., Part A: Polym. Chem. 2007, 45, 2755.

34. Kasperczyk, J.; Bero, M.; Makromol. Chem. 1991, 192, 1777.

35. Bero, M.; Kasperczyk, J.; Adamus, G.; Makromol. Chem. 1993, 194, 907.

36. Kasperczyk, J.; Bero, M.; Makromol. Chem. 2003, 194, 913.

37. Castro, M. L.; Wang, S. H.; Polym. Bull. 2003, 51, 151.

38. Nihant, N.; Schugens, Ch.; Grandfils, Ch.; Jérôme, R.; Teyssié, Ph.; Pharm. Res. 1994, 11, 1479.

39. Bouillot, P.; Babak, V.; Dellacherie, E.; Pharm. Res. 1999, 16, 148.

40. Freytag, T.; Dashevsky, A.; Tilman, L.; Hardee, G. E.; Bodmeier, R.; J. Controlled Release 2000, 69, 197.

41. Rosa, G. D.; Iommelli, R.; Rotonda, M. I. L.; Quaglia, F.; J. Controlled Release 2000, 69, 283.

42. Zhou, S.; Deng, X.; Yang, H.; Biomaterials 2003, 24, 3563. 